\title{
Work Related Risk Factors for Neck, Shoulder and Arms Complaints: A Cohort Study Among Dutch Computer Office Workers
}

\author{
Shahla Eltayeb - J. Bart Staal - Amar Hassan • \\ Rob A. de Bie
}

Published online: 15 August 2009

(C) The Author(s) 2009. This article is published with open access at Springerlink.com

\begin{abstract}
Introduction This study aims to investigate the relationship between work-related physical and psychosocial characteristics and complaints of the neck, shoulder and forearm/hands. Methods Data were used from a prospective Dutch cohort study among computer office workers with a follow-up period of 2 years. The study was conducted among 264 computer users. Physical and psychosocial risk factors were tested to predict the occurrence of neck, shoulder and forearm/hands complaints. Bivariate and multivariable logistic regression was used to identify the association between risk factors and outcome variables. Results The 2 year follow-up prevalence rates with 95\% CI for neck complaints were $0.31(0.28-0.37)$, for shoulder complaints $0.33(0.27-0.39)$ and for forearm/hands complaints $0.21(0.14-0.28)$. Four main predictors for the occurrence of neck and shoulder complaints were identified: (1) Irregular head and body posture [OR: $1.1(1.0-1.2)$ $P=0.04]$; (2) task difficulty (job demands) [OR: 1.2 (1.01.5) $P=0.01$ ]; (3) number of working hours/day with the computer [OR: $1.20(1.0-1.4) P=0.03$ ]; and (4) having had a previous history of complaints [OR: $7.2(3.8-13.2)$
\end{abstract}

\footnotetext{
S. Eltayeb $(\bowtie) \cdot$ J. B. Staal · R. A. de Bie

Department of Epidemiology and Caphri Research School, Maastricht University, PO Box 616, 6200 MD Maastricht, The Netherlands

e-mail: s_eltyeb@hotmail.com

J. B. Staal

e-mail: Bart.Staal@EPID.unimaas.nl

R. A. de Bie

e-mail: RA.deBie@EPID.unimaas.nl

S. Eltayeb - A. Hassan

School of Physiotherapy, Ahfad University for Women,

PO Box 167, Omdurman, Sudan

e-mail: ammmarhasssan@hotmail.com
}

$P=0.01]$. Two predictors were identified for forearm/ hands complaints: time pressure (job demands) [OR: 1.20 (1.0-1.4) $P=0.03]$ and having had a previous history of complaints [OR: 7.1 (3.5-14.1) $P=0.06$ ]. Conclusion This longitudinal study suggests that risk factors of upper musculoskeletal complaints in computer workers consist of a mixture of physical and psychosocial characteristics.

Keywords Risk factors .

Neck shoulder and forearm/hands · Complaints

\section{Introduction}

Musculoskeletal upper extremity symptoms and complaints of neck, shoulder and arms are common in the general population and among computer users in many industrialized countries [1, 2]. In recent years, computer-related office work has intensified in western developed countries. In Germany for example the 2004 census revealed that computer related work constituted a large part of the daily working routine for approximately 21 million people (59\% of all those with paid work) [2]. The etiology of neck, shoulder and forearm/hands complaints in computer workers is still not completely understood. Several risk factors related to different physical exposures at work and psychosocial conditions have been identified as potential causes for neck, shoulder and forearm/hands complaints. These exposures can be physical exposures related to static neck and arm postures, repetitive tasks, workplace design [3, 4] and also psychosocial factors related to job characteristics, high quantitative job demands, having little influence on one's work situation, and limited support from coworkers or supervisors [5-7]. Fewer studies have investigated the interaction between psychical/ergonomic and psychosocial 
factors for example the concept of work style $[8,9]$. Furthermore, individual factors (e.g. age, previous symptoms, etc.) have also been discussed in the literature as potential risk factors for these complaints. Hence, an etiological model explaining shoulder and neck and forearm complaints should consist of both physical and psychosocial factors at work [10].

We conducted a longitudinal cohort study among Dutch computer office workers. The psychosocial risks factors measured in this study were derived from the Karasek model [11-14]. The main thrust of this model, the Job DemandControl-Model, is that psychological strain does not result not from a single aspect of the work environment (such as a heavy workload or other job stressors), but from a joint effect of the level of job demands and the degree of autonomy or control that employees are able to exercise over their work. The job demands construct is the measure of stressors, such as work load demands which are present in the work environment [14]. The construct of control refers to the amount of influence that workers have over when and how they perform their work. In the Job Demand-Control-Model, these two constructs interact with each other to create job strain [14]. The theory was expanded further by adding a third construct: the social support which buffers against the negative impact of high strain $[15,16]$. Bongers et al. [6] have identified an association between the decision latitude and upper extremity complaints. The current study will test the main constructs in the Karasek model: i.e. job demands, job control and social support, and also job strain.

In addition to previous studies, the current prospective study aims to analyze the presence of neck, shoulder and forearm/hands complaints in relation to effects of both exposures to physical factors (i.e. work station and body posture) and to psychological factors (job demands, job control, social support and strain).

Accordingly, this study attempts to test the following research questions:

1. To what extent are job demands, job control, social support and job strain in the workplace, associated with the occurrence of symptoms in the neck, shoulder and forearm/hands?

2. To what extent are physical body posture and the design of the workplace associated with the occurrence of symptoms in the neck, shoulder and forearm/hands?

\section{Methods}

Participants and Setting

Study data were derived from a prospective longitudinal cohort study with 24 months follow-up. This study was conducted between December 1999 and January 2002 among computer office workers at the National Social Security Institution GAK (Gemeentelijk Administratie Kantoor) in Maastricht and Heerlen in the Netherlands. In December 1999 the total eligible working population at the GAK was approached. Out of 600 employees 268 responded to the questionnaire at baseline. The occurrences of complaints were assessed at 24 months follow-up; the same procedure of data collection reported in our previous publication was followed [17]. The study protocol was approved by the Medical ethical committee of Maastricht University Hospital.

\section{Data Source and Measurement}

Data were collected by means of a structured questionnaire: the Maastricht Upper extremity Questionnaire (MUEQ) [17]. Risk factor assessment considered various potential work-related physical and psychological risk factors. The MUEQ has been shown to posses satisfactorily psychometric characteristics (i.e. factor structure and internal consistency) which has been extensively reported elsewhere [17]. An English language version of the MUEQ has been reported in our previous publication [17]. The items in this questionnaire were mainly scored on a five point scale (completely true-completely false) or a dichotomous scale (yes-no).

\section{Potential Risk Factors}

\section{Work-Related Physical Factors}

The workstation scale included two subscales covering the workers perception of the office equipment (4 items, range $0-8$ points). This subscale had a Cronbach's alpha of 0.51 and the values of the item-total correlations ranged from 0.14 to 0.32 . The second subscale was the computer position ( 2 items, range $0-4$ points). The Cronbach's alpha of this subscale was 0.75 and the item-total correlation of this sub-scale was 0.59 . The first subscale asks the participants to specify the desk position of their keyboard and the screen position. The use of an arm/wrist support during keyboard use was also asked. Furthermore, the participants stated whether their chair could be adjusted to suit them. The subscale on computer position contained two items on the position of the keyboard and computer screen.

The body position scale was subdivided into two subscales: awkward body posture (5 items, range $0-25$ points) and irregular head and body posture ( 3 items, range $0-15$ points). This awkward body posture subscale had a Cronbach's alpha of 0.71 and the item-total correlations of this scale ranged from 0.30 to 0.57 . The irregular head and body posture subscale had a Cronbach's alpha of 0.54 and item-total correlations ranging from 0.38 to 0.45 . 
Further, the average number of working hours per day with computers was also considered to be a potential risk factor. We subdivided this factor in three categories: i.e. $>2.5,3-5$ and $<5 \mathrm{~h}$.

\section{Work Related Psychosocial Factors}

The MUEQ includes scales on job demands, job control, social support. For job demands two subscales were distinguished by the MUEQ: task difficulty ( 2 items, range 010 points) and job pressure (5 items, range 0-25 points). The Cronbach's alpha of the task difficulty subscale was 0.84 and the item-total correlation was 0.54. The Cronbach's alpha of the job pressure subscale was 0.80 and the item-total correlations ranged from 0.50 to 0.75 . Job control was covered by two subscales dealing with decision authority (5 items, range $0-25$ points) and skill discretion (4 items, range 0-20 points). The Cronbach's alpha of the decision authority subscale was 0.76 and the item-total correlation ranged from 0.37 to 0.61 . The Cronbach's alpha of the skill discretion subscale was 0.69 and item-total correlations ranged from 0.28 to 0.51 . For social support two subscales were used, one about the relationship among co-workers and between workers and supervisors (6 items, range $0-30$ points) and one about work flow ( 2 items, range 0-10 points). The Cronbach's alpha of the social support subscale was 0.80 and item-total correlations ranged from 0.58 to 0.67 . The Cronbach's of the work flow subscale was 0.60 and item-total correlations ranged from 0.28 to 0.38 .

The job strain variable was calculated by dividing the demands over control [18], i.e. task difficulty over the decision authority. These two subscales were selected as they have a higher explained variance compared to job pressure and skill discretion according to the factor analysis we performed earlier [17].

\section{Potential Confounders}

Age, sex and previous history of complaints were regarded as potential confounders, which means that they were both considered as potential independent risk factors of neck, shoulder and forearm/hands complaints and as being associated with other risk factors.

\section{Outcome Variables}

The outcome of the study was the occurrence (yes/no) of complaints of the neck, shoulder and forearm/hands (the questions were asked for each body region separately) with a duration of at least one week during the previous 12 months. This was measured 24 months after baseline. The results are presented for neck, shoulder and forearm/ hands separately.

\section{Statistical Methods}

Logistic regression was used to study the association between risk factors and outcome variables. Associations were considered statistically significant if $P \leq 0.05$ unless stated otherwise.

First, bivariate associations of all risk factors were investigated, separately for neck, shoulder and forearm/ hand complaints. Second, to check for collinearity between the different predictor variables we calculated the Variance Inflation Factors (VIF) and the Tolerance. Collinearity was assumed to be present if VIF was higher than 10 and Tolerance was lower than 0.1. Further, the correlation coefficients between the risk factors and the outcome were calculated. If co-linearity was present, the risk factor with the highest correlation with the outcome was used for the multivariable analysis. Third, a multivariable analysis was performed including all potential risk factors in addition to sex, age and previous history of complaints as potential confounders. If there were potential confounders with $P>0.20$ the potential confounder with the highest $P$-value was removed and the model was run again. This step was repeated until no confounders with $P$-values higher than 0.20 were left in the model. The 'explained variance' of each of the multivariable logistic regression models was calculated by means of Nagelkerke's $R^{2}$ and the goodness of fit by means of the Hosmer and Lemeshow goodness-of fit test.

\section{Results}

Study Population

Of the total 268 baseline respondents the participation rate at follow-up was $98 \%$. Seventy-six percent of the study population was employed fulltime, working 5 days per week $8 \mathrm{~h}$ per day. Forty-nine percent of the study population was involved in computer work for at least $6 \mathrm{~h}$ per day. About $50 \%$ of the study participants were male (Table 1).

\section{Prevalence}

The prevalence rate at 24 month follow-up was detected by the number of complaint cases divided by the number of 
Table 1 Descriptive characteristics of the study population $(n=264)$

\begin{tabular}{lll}
\hline \multicolumn{1}{l}{} & $\begin{array}{l}\text { Females } \\
(n=133)(\%)\end{array}$ & $\begin{array}{l}\text { Males } \\
(n=131)(\%)\end{array}$ \\
\hline $\begin{array}{l}\text { Numbers of working hours/day } \\
4-7 \mathrm{~h}\end{array}$ & 20.6 & 02.0 \\
$8 \mathrm{~h}$ & 08.4 & 03.0 \\
More than 8 h & 71.0 & 94.7 \\
Numbers of working hours with computer/day & \\
3-5 h & 15.4 & 26.0 \\
6-8 h & 28.5 & 29.0 \\
$>8$ h & 56.2 & 45.0 \\
Numbers of working years in current position & \\
6 months to 1 year & 23.8 & 20.3 \\
2-4 years & 43.8 & 41.4 \\
5 years and more & 14.6 & 18.8 \\
Baseline complaints & & \\
Neck complaints & 24 & 42 \\
Shoulder complaints & 20 & 42 \\
Forearm/hands complaints & 12.1 & 13.6 \\
\hline
\end{tabular}

Table 2 Prevalence rates at 24 months follow-up for neck, shoulder and forearm/hands complaints

\begin{tabular}{lll}
\hline Body region & $\begin{array}{l}\text { Prevalence }(95 \% \mathrm{CI}) \text { at } \\
12 \text { months }(n=264)\end{array}$ & $\begin{array}{l}\text { Prevalence }(95 \% \mathrm{CI}) \text { at } \\
24 \text { months }(n=264)\end{array}$ \\
\hline Neck & $0.33(0.27-0.39)$ & $0.31(0.28$ to 0.37$)$ \\
Shoulder & $0.31(0.28-0.37)$ & $0.33(0.27$ to 0.39$)$ \\
Forearm/hands & $0.25(0.15-0.31)$ & $0.21(0.14$ to 0.28$)$ \\
\hline
\end{tabular}

participants at follow-up. The prevalence rates for neck complaints were 0.31 (95\% CI 0.28-0.37), for shoulder complaints 0.33 (95\% CI 0.27-0.39) and for forearm/hands complaints 0.21 (95\% CI 0.14-0.28) (Table 2).

\section{Potential Risk Factors}

\section{Neck Complaints}

According to the bivariate analyses awkward head and body posture [OR: $0.1(0.01-0.18) P=0.01]$, irregular body posture [OR: $0.2(0.11-0.30) P=0.01]$, and task difficulty [OR: $0.1(0.10-0.32) P=0.05]$, were significantly associated with neck complaints. The results of the multivariable analyses indicated that the presence of neck complaints was significantly associated with irregular head and body posture [OR: $1.1(1.1-1.2) P=0.04]$, task difficulty [OR: $1.2(1.1-1.5) P=0.01]$, the number of working hours with the computer [OR: $1.2(1.0-1.4)$ $P=0.03$ ] and previous history of neck complaints [OR: 7.2 (3.8-13.6) $P=0.01$ ] (Table 3). The Nagelkerke's $R^{2}$ was 0.37 and the Hosmer-Lemeshow goodness-of-fit test was not significant $\left(\chi^{2}=6.42, P=0.600\right)$.

\section{Shoulder Complaints}

The bivariate analyses showed a significant association between shoulder complaints and irregular head and body posture [OR: $0.2(0.15-0.41) P=0.01]$, previous history of complaints [OR: $0.09(0.36-1.56) P=0.01]$, and personal computer placement [OR: $0.1(0.07-0.17) P=0.03]$. The results of the multivariable analyses indicated that shoulder complaints were significantly associated with irregular head and body posture [OR: $1.1(1.0-1.3) P=0.02]$, task difficulty [OR: $1.2(0.9-1.40) P=0.05]$, the average number of hours working with the computer per day [OR: 1.2 (1.0-1.50) $P=0.01]$ and previous history of neck complaints [OR: 19.2 (9.8-28.6) $P=0.00$ ] (Table 4). The Nagelkerke's $R^{2}$ was 0.46 and the Hosmer-Lemeshow goodness-of-fit test was not significant $\left(\chi^{2}=3.92, P=0.864\right)$.
Table 3 Psychological and physical risk factors for neck complaints adjusted for age, sex and history of complaints

\begin{tabular}{|c|c|c|c|c|}
\hline \multirow[t]{2}{*}{ Risk factors } & \multicolumn{2}{|c|}{ Bivariate analysis } & \multicolumn{2}{|c|}{ Multivariable analysis } \\
\hline & OR $(95.0 \% \mathrm{CI})$ & $P$-value & OR $(95.0 \% \mathrm{CI})$ & $P$-value \\
\hline Computer working hours/day & $1.1(0.13-0.68)$ & 0.07 & $1.2(1.0-1.41)$ & 0.03 \\
\hline Previous history of complaints & $0.1(0.01-0.51)$ & 0.01 & $7.2(3.8-13.60)$ & 0.00 \\
\hline Equipment position & $1.7(0.01-0.10)$ & 0.08 & $0.8(0.6-1.22)$ & 0.47 \\
\hline Personal computer placement & $1.3(0.02-0.14)$ & 0.16 & $1.2(0.7-2.23)$ & 0.38 \\
\hline Awkward body posture & $0.1(0.01-0.18)$ & 0.01 & $1.0(0.9-1.11)$ & 0.77 \\
\hline Irregular head and body posture & $0.2(0.11-0.30)$ & 0.01 & $1.1(1.0-1.21)$ & 0.04 \\
\hline Decision authority & $1.8(0.01-1.02)$ & 0.06 & $0.9(0.8-1.00)$ & 0.22 \\
\hline Skills discretion & $1.1(0.01-0.05)$ & 0.31 & $0.9(0.8-1.22)$ & 0.98 \\
\hline Job pressure & $1.0(0.02-0.06)$ & 0.25 & $1.0(0.9-1.03)$ & 0.97 \\
\hline Task difficulty & $0.1(0.10-0.32)$ & 0.05 & $1.2(1.0-1.51)$ & 0.01 \\
\hline Social support & $0.8(0.01-0.92)$ & 0.41 & $1.0(0.9-1.10)$ & 0.12 \\
\hline Work flow & $1.1(0.05-0.09)$ & 0.10 & $0.9(0.7-1.10)$ & 0.76 \\
\hline Job strain & $0.4(0.20-0.32)$ & 0.66 & $2.6(0.11-16.2)$ & 0.72 \\
\hline
\end{tabular}


Table 4 Results of multivariable analysis of psychological and physical predictive risk factors for shoulder complaints adjusted for age, sex and history of complaints
Table 5 Results of multivariable analysis of psychological and physical predictive risk factors for forearm/hands complaints adjusted for age, sex and history of complaint

\begin{tabular}{|c|c|c|c|c|}
\hline \multirow[t]{2}{*}{ Risk factor } & \multicolumn{2}{|c|}{ Bivariate analysis } & \multicolumn{2}{|c|}{ Multivariable analysis } \\
\hline & OR $(95 \% \mathrm{CI})$ & $P$-value & OR $(95 \% \mathrm{CI})$ & $P$-value \\
\hline Computer working hours/day & $2.3(0.05-1.62)$ & 0.09 & $1.2(1.0-1.50)$ & 0.01 \\
\hline Previous history of complaints & $0.9(0.36-1.56)$ & 0.01 & $19.2(9.8-28.6)$ & 0.00 \\
\hline Equipment position & $0.7(0.36-0.78)$ & 0.46 & $0.8(0.6-1.23)$ & 0.47 \\
\hline Personal computer placement & $0.1(0.07-0.17)$ & 0.05 & $1.2(0.7-2.20)$ & 0.38 \\
\hline Awkward body posture & $0.2(0.15-0.41)$ & 0.07 & $1.0(0.9-1.10)$ & 0.77 \\
\hline Irregular head and body posture & $0.2(0.15-0.41)$ & 0.01 & $1.1(1.0-1.31)$ & 0.02 \\
\hline Decision authority & $1.3(0.25-0.91)$ & 0.19 & $0.9(0.8-1.00)$ & 0.22 \\
\hline Skills discretion & $0.6(0.24-042)$ & 0.51 & $0.9(0.8-1.21)$ & 0.98 \\
\hline Job pressure & $1.7(0.02-0.27)$ & 0.08 & $0.1(0.9-1.01)$ & 0.97 \\
\hline Task difficulty & $1.5(0.07-0.60)$ & 0.12 & $1.2(0.9-1.40)$ & 0.06 \\
\hline Social support & $0.4(0.17-0.52)$ & 0.62 & $1.0(0.9-1.10)$ & 0.12 \\
\hline Work flow & $1.4(0.02-0.64)$ & 0.60 & $0.9(0.7-1.10)$ & 0.76 \\
\hline Job strain & $0.7(0.28-0.62)$ & 0.94 & $27.8(16.2-36.1)$ & 0.28 \\
\hline
\end{tabular}

\begin{tabular}{|c|c|c|c|c|}
\hline \multirow[t]{2}{*}{ Risk factor } & \multicolumn{2}{|c|}{ Bivariate analysis } & \multicolumn{2}{|c|}{ Multivariable analysis } \\
\hline & OR $(95 \% \mathrm{CI})$ & $P$-value & OR $(95 \% \mathrm{CI})$ & $P$-value \\
\hline Computer working hours/day & $0.8(0.45-1.46)$ & 0.50 & $0.96(0.79-1.17)$ & 0.36 \\
\hline Previous history of complaints & $6.9(3.41-13.9)$ & 0.01 & $7.1(3.5-14.20)$ & 0.00 \\
\hline Equipment position & $2.0(0.93-2.78)$ & 0.40 & $0.8(0.6-1.21)$ & 0.47 \\
\hline Personal computer placement & $0.5(0.05-0.85)$ & 0.61 & $1.1(0.6-1.92)$ & 0.67 \\
\hline Awkward body posture & $2.0(0.07-0.23)$ & 0.01 & $1.0(0.9-1.10)$ & 0.88 \\
\hline Irregular head and body posture & $0.1(0.09-0.36)$ & 0.05 & $0.9(0.8-1.01)$ & 0.27 \\
\hline Decision authority & $1.5(0.25-0.31)$ & 0.11 & $0.9(0.8-1.02)$ & 0.34 \\
\hline Skills discretion & $1.6(0.75-1.75)$ & 0.09 & $0.9(0.8-1.25)$ & 0.32 \\
\hline Job pressure & $1.7(0.02-0.27)$ & 0.08 & $0.9(0.8-1.02)$ & 0.54 \\
\hline Task difficulty & $1.5(0.07-0.60)$ & 0.12 & $1.0(0.9-1.30)$ & 0.05 \\
\hline Social support & $1.1(0.05-0.18)$ & 0.24 & $1.0(0.9-1.11)$ & 0.80 \\
\hline Work flow & $1.2(0.10-1.43)$ & 0.21 & $1.0(0.8-1.21)$ & 0.73 \\
\hline Job strain & $0.3(0.23-0.34)$ & 0.97 & $2.5(1.6-13.10)$ & 0.34 \\
\hline
\end{tabular}

\section{Forearm/Hands Complaints}

The bivariate analyses showed significant associations between forearm/hands complaints and irregular head and body posture [OR: $0.1(0.09-0.36) P=0.05]$, awkward body posture [OR: $2.0(0.07-0.23) P=0.01]$ and having had a previous history of complaints [OR: 6.9 (3.41-13.9) $P=0.00]$. The results of the multivariable analyses indicated that forearm/hands complaints were significantly associated with and both task difficulty (job demands) [OR: 1.0 (0.9-1.30) $P=0.05]$ and having had a previous history of complaints [OR: $7.1(3.5-14.20) P=0.00$ ] (Table 5). The Nagelkerke's $R^{2}$ was 0.26 and the Hosmer-Lemeshow goodness-of-fit test was not significant $\left(\chi^{2}=7.26\right.$, $P=0.508)$.

\section{Discussion}

In this longitudinal study among computer office workers, we found that the report of complaints in the neck region was similar to shoulder complaints, however, much higher than forearms/hands complaints, which corresponds with the results of previous studies. Boet et al. found in a Dutch cohort of general practice patients incidence rates of 23.1 cases per 1,000 person-years for neck symptoms, followed by 19.0 cases per 1,000 person-years for shoulder symptoms [19]. Furthermore, a survey in the Netherlands showed that in 2002 and 2004, 28\% of the working population reported neck/shoulder or elbow/wrist/hand symptoms in the previous 12 months [10] and that these symptoms were at least partly caused by work. Another study in the USA [4] 
indicated that among 416 employees $63 \%$ reported neck shoulder pain compared to $34 \%$ reporting arm or hand pain.

Neck, shoulder and forearms/hand complaints were associated with both work-related psychosocial and physical factors. Different studies have taken physical and psychosocial work related factors into account when studying upper extremity complaints with mixed results $[1,10,20-$ 24]. The current study showed that among the work related physical factors significant associations were found between irregular head and body posture and neck, shoulder and forearms/hands complaints. The irregularity was identified as either sitting with a twisted trunk or in a symmetrical position or with the neck held in a bent position. In the scientific literature their seems to be some consensus on poor ergonomic conditions at workstations contributing to musculoskeletal symptoms or disorders [22, 25]. Ariens et al. indicated that holding the neck in a forward bent posture for a prolonged period of time, and repeatedly working in the same position for a prolonged period of time were both significantly associated with neck pain. Other studies showed $[26,27]$ that the odds ratios for neck pain increased with the time spent working in a sitting position, suggesting a dose-response relation between sitting posture and neck pain. According to Ortiz-Hernandez et al. [28], remaining seated for long periods, usually accompanied by a bent curvature of the spine, increases pressure on vertebral discs, stresses ligaments, and provokes muscle pain. The association found with both neck, shoulder and forearm complaints indicates that whatever irregularity exists (i.e. either a twisted, bended or asymmetrical position) it predicted the presence of complaints in this study population.

Furthermore, previous history of complaints was significantly associated with the presence of current complaints. This result corresponds with findings from Smedley et al. [29] and Bongers et al. [10] who found in a longitudinal study that the strongest predictor of incident neck/shoulder pain was previous history of the symptoms.

Psychosocial factors have been discussed as predictors in previous studies $[6,13,30]$. In a systematic review it has been found that, high job demands, low decision latitude, time pressure, mental stress, job dissatisfaction, high workload, and lack of social support from colleagues and superiors were suggested as risk factors for upper extremity musculoskeletal disorders [6, 13]. In the current study seven variables adapted from the Karasek model were tested (i.e. job demands (task difficulty and work pressure), job control (decision authority and skill discretion), social support (support between coworkers and supervisors and work flow) and job strain. The results found support for the association between task difficulties and complaints in the neck and shoulder. This finding is consistent with other prospective studies of neck pain which also found that job demands were a risk factor $[13,31]$.
The multivariable model indicated that a significant association was found between upper extremity musculoskeletal complaints and both the job demands and head and body posture. These findings are in line with recent studies examining the combined and/or interactive effects of both biomechanical/physical factors and occupational psychosocial factors [32-34]. The interaction among psychosocial stressors, work demands, ergonomic exposures, and the complex individual response to these workplace factors refer to someone's work style. This work style model is based upon the hypothesis that how an individual performs his/her work tasks in reaction to increased work demands may either increase the likelihood of developing upper extremity symptoms or exacerbate and maintain preexisting symptoms $[8,33]$. Although the current study did not test the work style construct, work style is, however, very much related to many of the findings in the current study in terms of the role of work demands and the biobehavioral response to these demands that can expose these workers to both biomechanical and psychosocial factors.

Generally, this study confirms the main findings of the literature $[10,17,22,24,35]$. Neck and shoulder complaints occurred significantly more often than complaints in the other parts of the upper extremities. Neck, and shoulder and forearm/hands complaints were positively associated with irregular head and body posture and job demands (i.e. task difficulty). The findings of the current study are based on the simultaneous consideration of various regions of the upper extremities and various risk factors.

However, there are some limitations that merit discussion. First, the report of complaints may have been biased due to the fact that subjects had to report neck or shoulder complaints that occurred in the past 12 months which might have introduced recall bias. Second, the measurement of ergonomic risk factors was subjective, and not based on actual measuring of the degree/level on neck position, distance from monitor by means of for example video recordings.

The study results suggest that intervention strategies aiming at reducing the occurrence of neck, shoulder and forearms complaints most likely have to take into account both ergonomic improvements and psychosocial aspects and the interaction between these two risk factors. Based on the results of this study, interventions should be aimed to reduce computer exposure and also toward improving ergonomic conditions. Further, one can cautiously postulate that the negative impact of work demands should be viewed not only from the perspective of autonomy (i.e. control on how and when tasks are performed) but also from the perspective of task difficulty and complexity such as perceived by the worker.

Acknowledgments We would like to thank the management, doctors and employees of the GAK (national unemployment insurance 
office) in Maastricht and Heerlen, The Netherlands, for their willingness to participate in this study.

Competing Interests The author(s) declare that they have no competing interests.

Open Access This article is distributed under the terms of the Creative Commons Attribution Noncommercial License which permits any noncommercial use, distribution, and reproduction in any medium, provided the original author(s) and source are credited.

\section{References}

1. Gerr F, Marcus M, Monteilh C. Epidemiology of musculoskeletal disorders among computer users: lesson learned from the role of posture and keyboard use. J Electromyogr Kinesiol. 2004;14: 25-31.

2. Klussmann A, Gebhardt H, Liebers F, Rieger MA. Musculoskeletal symptoms of the upper extremities and the neck: a crosssectional study on prevalence and symptom-predicting factors at visual display terminal (VDT) workstations. BMC Musculoskelet Disord. 2008;9:96.

3. Andersen JH, Harhoff M, Grimstrup S, Vilstrup I, Lassen CF, Brandt LP, et al. Computer mouse use predicts acute pain but not prolonged or chronic pain in the neck and shoulder. Occup Environ Med. 2008;65:126-31.

4. Gerr F, Marcus M, Ensor C, Kleinbaum D, Cohen S, Edwards A, et al. A prospective study of computer users: I. Study design and incidence of musculoskeletal symptoms and disorders. Am J Ind Med. 2002;41:221-35.

5. Dellve L, Lagerstrom M, Hagberg M. Work-system risk factors for permanent work disability among home-care workers: a casecontrol study. Int Arch Occup Environ Health. 2003;76:216-24.

6. Bongers PM, Kremer AM, ter Laak J. Are psychosocial factors, risk factors for symptoms and signs of the shoulder, elbow, or hand/wrist?: a review of the epidemiological literature. Am J Ind Med. 2002;41:315-42.

7. Van den Heuvel SG, van der Beek AJ, Blatter BM, Hoogendoorn WE, Bongers PM. Psychosocial work characteristics in relation to neck and upper limb symptoms. Pain. 2005;114:47-53.

8. Feuerstein M, Nicholas RA, Huang GD, Haufler AJ, Pransky G, Robertson M. Workstyle: development of a measure of response to work in those with upper extremity pain. J Occup Rehabil. 2005;15:87-104.

9. Nicholas RA, Feuerstein M, Suchday S. Workstyle and upperextremity symptoms: a biobehavioral perspective. J Occup Environ Med. 2005;47:352-61.

10. Bongers PM, Ijmker S, van den Heuvel S, Blatter BM. Epidemiology of work related neck and upper limb problems: psychosocial and personal risk factors (part I) and effective interventions from a bio behavioural perspective (part II). J Occup Rehabil. 2006;16: 279-302.

11. Schnall PL, Landsbergis PA, Baker D. Job strain and cardiovascular disease. Annu Rev Public Health. 1994;15:381-411.

12. Karasek R, Brisson C, Kawakami N, Houtman I, Bongers P, Amick B. The Job Content Questionnaire (JCQ): an instrument for internationally comparative assessments of psychosocial job characteristics. J Occup Health Psychol. 1998;3:322-55.

13. Hannan LM, Monteilh CP, Gerr F, Kleinbaum DG, Marcus M. Job strain and risk of musculoskeletal symptoms among a prospective cohort of occupational computer users. Scand J Work Environ Health. 2005;31:375-86.

14. Karasek R, Baker D, Marxer F, Ahlbom A, Theorell T. Job decision latitude, job demands, and cardiovascular disease: a prospective study of Swedish men. Am J Public Health. 1981:71:694-705.

15. Snyder LA, Krauss AD, Chen PY, Finlinson S, Huang YH. Occupational safety: application of the job demand-control-support model. Accid Anal Prev. 2008;40:1713-23.

16. Sanne B, Mykletun A, Dahl AA, Moen BE, Tell GS. Testing the job demand-control-support model with anxiety and depression as outcomes: the Hordaland health study. Occup Med (Oxford, England). 2005;55:463-73.

17. Eltayeb S, Staal JB, Kennes J, Lamberts PH, de Bie RA. Prevalence of complaints of arm, neck and shoulder among computer office workers and psychometric evaluation of a risk factor questionnaire. BMC Musculoskelet Disord. 2007;8:68.

18. Kryger AI, Andersen JH, Lassen CF, Brandt LP, Vilstrup I, Overgaard E, et al. Does computer use pose an occupational hazard for forearm pain; from the NUDATA study. Occup Environ Med. 2003;60:e14.

19. Bot SD, van der Waal JM, Terwee CB, van der Windt DA, Scholten RJ, Bouter LM, et al. Predictors of outcome in neck and shoulder symptoms: a cohort study in general practice. Spine. 2005;30:E459-70.

20. Punnett L, Bergqvist U. Musculoskeletal disorders in visual display unit work: gender and work demands. Occup Med. 1999;14:113-24.

21. Marcus M, Gerr F, Monteilh C, Ortiz DJ, Gentry E, Cohen S, et al. A prospective study of computer users: II. Postural risk factors for musculoskeletal symptoms and disorders. Am J Ind Med. 2002;41:236-49.

22. IJmker S, Huysmans MA, Blatter BM, van der Beek AJ, van Mechelen W, Bongers PM. Should office workers spend fewer hours at their computer? A systematic review of the literature. Occup Environ Med. 2007;64(4):211-22.

23. Gerr F, Letz R, Landrigan PJ. Upper-extremity musculoskeletal disorders of occupational origin. Annu Rev Public Health. 1991;12:543-66.

24. Korhonen T, Ketola R, Toivonen R, Luukkonen R, Hakkanen M, Viikari-Juntura E. Work related and individual predictors for incident neck pain among office employees working with video display units. Occup Environ Med. 2003;60:475-82.

25. Gerr F, Monteilh CP, Marcus M. Keyboard use and musculoskeletal outcomes among computer users. J Occup Rehabil. 2006;16:265-77.

26. Nakazawa T, Okubo Y, Suwazono Y, Kobayashi E, Komine S, Kato N, et al. Association between duration of daily VDT use and subjective symptoms. Am J Ind Med. 2002;42:421-6.

27. Skov T, Borg V, Orhede E. Psychosocial and physical risk factors for musculoskeletal disorders of the neck, shoulders, and lower back in salespeople. Occup Environ Med. 1996;53:351-6.

28. Ortiz-Hernandez L, Tamez-Gonzalez S, Martinez-Alcantara S, Mendez-Ramirez I. Computer use increases the risk of musculoskeletal disorders among newspaper office workers. Arch Med Res. 2003;34:331-42.

29. Smedley J, Inskip H, Trevelyan F, Buckle P, Cooper C, Coggon D. Risk factors for incident neck and shoulder pain in hospital nurses. Occup Environ Med. 2003;60:864-9.

30. Hoogendoorn WE, van Poppel MN, Bongers PM, Koes BW, Bouter LM. Systematic review of psychosocial factors at work and private life as risk factors for back pain. Spine. 2000;25:2114-25.

31. Ariens GA, Bongers PM, Hoogendoorn WE, van der Wal G, van Mechelen W. High physical and psychosocial load at work and sickness absence due to neck pain. Scand J Work Environ Health. 2002;28:222-31.

32. Harrington $\mathrm{CB}$, Siddiqui A, Feuerstein M. Workstyle as a predictor of pain and restricted work associated with upper extremity disorders: a prospective study. J Hand Surg Am. 2009;34:724-31. 
33. Huang GD, Feuerstein M, Kop WJ, Schor K, Arroyo F. Individual and combined impacts of biomechanical and work organization factors in work-related musculoskeletal symptoms. Am J Ind Med. 2003;43:495-506.

34. Feuerstein M, Shaw WS, Nicholas RA, Huang GD. From confounders to suspected risk factors: psychosocial factors and work- related upper extremity disorders. J Electromyogr Kinesiol. 2004; $14: 171-8$.

35. Juul-Kristensen B, Sogaard K, Stroyer J, Jensen C. Computer users' risk factors for developing shoulder, elbow and back symptoms. Scand J Work Environ Health. 2004;30:390-8. 